\title{
Variability in the Levels of Vitamin D by Age, Gender, and Race/Ethnicity: Data from National Health and Nutrition Examination Survey 2007-2010
}

\section{Jain RB}

2959 Estate View Court, Dacula, GA 30019, USA

*Corresponding author: Jain RB, 2959 Estate View Court, Dacula, GA 30019, USA, Tel: 001-910-729-1049, E-mail: Jain.ram.b@gmail.com

Citation: Jain RB (2016) Variability in the levels of vitamin D by age, gender, and race/ethnicity: Data from National Health and Nutrition Examination Survey 2007-2010. J Nutr Health Sci 3(2): 203. doi: 10.15744/2393-9060.3.203

Received Date: March 19, 2016 Accepted Date: May 23, 2016 Published Date: May 25, 2016

\begin{abstract}
Data from National Health and Nutrition Examination Survey were used to investigate variability in the levels of vitamin D (25OHD) by age, gender, and race/ethnicity for the general U.S. population for 2007-2010. Data were analyzed separately for those aged 1-11, $12-19,20-64$, and $\geq 65$ years. For each of these age groups, linear regression models with log 10 transformed values of $25 \mathrm{OHD}$ levels as the dependent variable and gender, race/ethnicity, smoking status, and obesity as categorical independent variables, and age in single years, poverty income ratio, and $\log 10$ transformed values of calcium and phosphorous as continuous independent variables were fitted. Among children aged 1-11 years and adolescents aged 12-19 years, males were found to have higher 25OHD levels than females $(\mathrm{p}<0.01)$. In general, irrespective of age, the order of 25OHD levels by race/ethnicity was found to be non-Hispanic whites $>$ Hispanics $>$ non-Hispanic blacks and obesity was found to be associated with lower levels of 25OHD levels among children, adolescents, and adults aged 20-64 years. Among those aged $>=20$ years, smoking was associated with lower levels of $25 \mathrm{OHD}$ ( $\mathrm{p}<0.01$ ). For children, age was negatively associated with $25 \mathrm{OHD}$ levels $(\mathrm{p}<0.01)$ and among adults aged $20-64$ years, age was positively associated with $25 \mathrm{OHD}$ levels $(\mathrm{p}=0.01)$. Irrespective of age, poverty income ratio was positively associated with $25 \mathrm{OHD}$ levels $(\mathrm{p}<=0.01)$.

Keywords: Age; Gender; Race/ethnicity; Smoking; Obesity
\end{abstract}

\section{Introduction}

Role of vitamin D in human health has been enhanced during the recent years. Vitamin D should no longer be thought of just as a nutrient necessary for the prevention of rickets among children but also essential for the overall health and well-being of humans Holick, et al. [1]. Positive association between bone mineral density and 25-hydroxyvitamin D (25OHD) levels has been reported by Gutiérrez, et al. among non-Hispanic whites (NHW) and Mexican Americans (MA) but not among non-Hispanic blacks (NHB) [2]. Negative association between the levels of 25OHD and fasting glucose, fasting insulin, and diabetes risk has been observed among NHW and MA but not in NHB. The likelihood of having metabolic syndrome among adolescents was reported to be significantly higher among those in the first tertile of $25 \mathrm{OHD}$ than those in the third tertile of $25 \mathrm{OHD}$ by Ganji, et al. and similar association was also documented by Maki, et al. [3,4]. Inverse associations between the levels of 25OHD and allostatic load (Frei, et al.) history of community acquired pneumonia (Quraishi, et al.) acute respiratory infections (Monlezun, et al.) anemia (Atkinson, et al.) systolic blood pressure (Williams, et al.) He, et al. unexplained elevation in (ALT Liangpunsakul, et al.) frailty among older adults (Wilhelm-Leen, et al.) self-reported peripheral neuropathy symptoms (Soderstrom, et al.) and psychiatric disorders among children aged 1-17 years (Zhang, et al.) have been reported using data from National Health and Nutrition Examination Survey (NHANES) [5-14]. Milman, et al. reported higher levels of vitamin D to be associated with delayed ageing because vitamin D levels may delay cognitive impairment [15]. Inverse association between 25OHD levels and all cause and cause specific mortality have also been reported Schmutz, et al. Zhao, et al. Deng, et al. Cheng, et al. Michos, et al. Bakhru, et al. [16-21]. However, Freedman, et al. used mortality linked data from NHANES 1988-2006 and concluded that their results did not support the hypothesis that $25 \mathrm{OHD}$ is associated with reduced cancer mortality, although cancer mortality in females was inversely associated with $25 \mathrm{OHD}$ in the summer/higher latitude group [22].

As reported above, data from NHANES (www.cdc.gov/nchs/nhanes.htm), conducted by the US Centers for Disease Control and Prevention have been comprehensively used to assess associations between 25OHD levels and a variety of health conditions [23]. NHANES provided data on 25OHD in serum for NHANES III conducted during 1988-1994 and then continuously since 2001. Data for continuous NHANES that began in 1999 are released in public domain every two years. The most recent data on 25OHD levels were made available for 2009-2010 wave of continuous NHANES. A radioimmunoassay (RIA) was used to measure 25OHD 
levels for 1988-1994, 2001-2002, 2003-2004, and 2005-2006 waves of NHANES. Starting with 2007-2008 wave of NHANES, $25 \mathrm{OHD}$ measurements were based in a LC-MS/MS assay. However, in order to enable researchers to study trends in 25OHD levels across the full spectrum of NHANES years, namely, from 1998 to 2010, selected serum samples from 1988-1994, 2001-2002, 20032004, and 2005-2006 were also analyzed by LC-MS/MS based assay (CDC, 2015) used for 2007-2010 data. Regression equations were developed to covert RIA based measurements to LC-MS/MS based measurements and these equations were used to obtain derived data for 1988-2006 and these derived data were released in public domain in October 2015 (CDC, 2015). Consequently, derived data for 1988-2006 and direct measurement data for 2007-2010 can "supposedly" be used to study trends in 25OHD measurements across 1988-2010. However, for those interested in direct RIA data, RIA based data for 1988-2006 are also available. In the past there have been quite a few publications that have used RIA based data for 1988-2006 NHANES.

Recently, Jain, et al. investigated how derived RIA based data for 2001-2006 were compatible with directly measured LC-MS/ MS based data for 2007-2010 [24]. Jain, et al. could not confirm compatibility between derived data for 2001-2006 and direct measurement data for 2007-2010 for studying trends in 25OHD levels, vitamin D deficiency rates, and vitamin D sufficiency rates because of unusually large shifts in these statistics between 2001-2006 and 2007-2010 [24]. For example for those aged $>=6$ years, while unadjusted mean (UM) 25OHD levels for 2001-2006 varied between 61.6 and $63.3 \mathrm{nmol} / \mathrm{L}$, for 2007-2010, UMs were 67.5 and $67.7 \mathrm{nmol} / \mathrm{L}$ for 2007-2008 and 2009-2010 respectively; and for children aged 6-11 years, vitamin D sufficiency rates (or $>=75$ $\mathrm{nmol} / \mathrm{L}$ ) varied between $23.1 \%$ and $28.6 \%$ for 2001-2006, they were $40.6 \%$ and $38.8 \%$ for 2007-2008 and 2009-2010 respectively. While Jain, et al. presented UMs, deficiency, and sufficiency rates for vitamin D, this study was undertaken to study variability in adjusted geometric mean vitamin D levels (AGMs) by age, gender, and race/ethnicity for 2007-2010 data [24]. Since, this is the first time that raw data for $25 \mathrm{OHD}$ levels based on LC-MS/MS are being presented, these data may be used to not only study variability in $25 \mathrm{OHD}$ levels by age, gender, and race/ethnicity but also to develop revised thresholds for Vitamin D deficiency and sufficiency levels based on LC-MS/MS assay.

\section{Materials and methods}

\section{Data source and data description}

Data from NHANES for the period 2007-2010 from demographic, body measures, standard chemistry profile, and vitamin D files were downloaded and match merged. Vitamin $D$ data were available for all those aged $\geq 1$ year and data for serum calcium and phosphorus were available for all those aged $\geq 12$ years. A total of 15812 participants with non-missing values of 25OHD were available for analysis. Detailed sample sizes are given in Table 1. Separate analyses were done for the age groups 1-11 ( $\mathrm{N}=3204)$, $12-19$ (2118), 20-64 ( $\mathrm{N}=7720)$, and $>=65(\mathrm{~N}=2770)$ years.

\begin{tabular}{|c|c|c|c|c|c|c|c|c|}
\hline & \multicolumn{2}{|c|}{ 1-11 Years } & \multicolumn{2}{|c|}{ 12-19 Years } & \multicolumn{2}{|c|}{ 20-64 Years } & \multicolumn{2}{|c|}{$65+$ Years } \\
\hline & $\mathrm{N}$ & $\%$ & $\mathrm{~N}$ & $\%$ & $\%$ & $\%$ & $\mathrm{~N}$ & $\%$ \\
\hline Total & 3204 & 100.0 & 2118 & 100.0 & 100.0 & 100.0 & 2770 & 100.0 \\
\hline Male & 1651 & 51.5 & 1136 & 53.6 & 53.6 & 48.0 & 1382 & 49.9 \\
\hline Female & 1553 & 48.5 & 982 & 46.4 & 46.4 & 52.0 & 1388 & 50.1 \\
\hline Non-Hispanic White & 996 & 31.1 & 683 & 32.2 & 32.2 & 43.9 & 1712 & 61.8 \\
\hline Non-Hispanic Black & 686 & 21.4 & 479 & 22.6 & 22.6 & 18.8 & 414 & 14.9 \\
\hline Hispanics & 1332 & 41.6 & 837 & 39.5 & 39.5 & 32.0 & 546 & 19.7 \\
\hline Other race/ethnicities & 190 & 5.9 & 119 & 5.6 & 5.6 & 5.2 & 98 & 3.5 \\
\hline Obese $^{*}$ & 540 & 16.9 & 426 & 20.1 & 20.1 & 38.1 & 967 & 34.9 \\
\hline Not Obese ${ }^{\star}$ & 2350 & 73.3 & 1650 & 77.9 & 77.9 & 61.1 & 1739 & 62.8 \\
\hline Nonsmoker ${ }^{* *}$ & & & 1857 & 87.7 & 87.7 & 70.4 & 2381 & 86.0 \\
\hline Smoker ${ }^{* *}$ & & & 258 & 12.2 & 12.2 & 29.4 & 383 & 13.8 \\
\hline
\end{tabular}

${ }^{*}$ May not sum to $100 \%$ because of missing values for obesity status

${ }^{* *}$ May not sum to $100 \%$ because of missing values for smoking status

Table 1: Unweighted sample sizes by age, gender, race/ethnicity, obesity and smoking statuses. Data from National Health and Nutrition Examination Survey for 2007-2010

It should be noted that data on demographics are collected from NHANES participants during an in-home interview. Self-reported data on age, gender, race, ethnicity, family income, family size, and other demographic variables are collected and used to compute variables like race/ethnicity and poverty income ratio before they are released in the public domain. For example, age is computed from self-reported or imputed data of birth (https://wwwn.cdc.gov/Nchs/Nhanes/2007-2008/DEMO_E.htm\#Data_Processing and_Editing). Race/ethnicity is computed from self-reported date on race and Hispanic origin. Poverty income ratio is computed by dividing self-reported family income by US government specified poverty guidelines specific to self-reported family size as well as appropriate year and state of residence (https://wwwn.cdc.gov/Nchs/Nhanes/2007-2008/DEMO_E.htm\#Data_Processing_ and_Editing). 
The sampling plan for NHANES generates data which are representative of the civilian, non-institutionalized U.S. population. Sampling weights are created in NHANES to account for the complex survey design, including oversampling, survey nonresponse, and post-stratification. All analyses conducted for this study incorporated sampling weights and design characteristics like information on stratification and clustering.

\section{Laboratory methodology}

Quantitative detections of 25-hydroxyvitamin D3 (25OHD3), 25-hydroxyvitamin D2 (25OHD2), and epi-25-hydroxyvitamin D3 (epi-25OHD3) were made by utilizing ultra-high performance liquid-chromatography mass spectrometer and 25OHD was used as the sum of 25OHD2 and 25OHD3. Details are available at http://wwwn.cdc.gov/Nchs/Nhanes/2007-2008/VID_E. htm\#Description_of_Laboratory_Methodology.

\section{Outcome variable}

Since the distributions of 25OHD were positively skewed for each of the four databases, namely, for those aged 1-11 years (skewness=0.50), 12-19 years (skewness $=0.80$ ), 20-64 years (skewness $=0.76$ ), and $65+$ years (skewness $=0.58$ ), all values of $25 \mathrm{OHD}$ were $\log 10$ transformed before using $25 \mathrm{OHD}$ as the dependent variable in each of the four models that were fitted.

\section{Covariates/Independent variables}

For each of the four regression models, gender (male, female), obesity (obese, not obese), and race/ethnicity (non-Hispanic white or NHW, non-Hispanic black or NHB, all Hispanics or HISP, other unclassified race/ethnicities or OTH) were used as categorical independent variables. For those aged $>=19$ years, obesity was defined as having a body mass index of $>=30 \mathrm{~kg} / \mathrm{m}^{3}$. For those aged $<19$ years, obesity was defined as being at or above the $95^{\text {th }}$ percentile of the gender-age specific distributions for the body mass index. In addition, for the models for those aged 12-19, 20-64, and 65+ years, smoking status was also used as an independent categorical variable. All those with serum cotinine levels of $<10 \mathrm{ng} / \mathrm{mL}$ were defined as non-smokers and all those with serum cotinine level of $>=10 \mathrm{ng} / \mathrm{mL}$ were defined as being smokers. Age and poverty income ratio (PIR) were used as continuous independent variables in all four models. In addition, for the models for those aged 12-19, 20-64, and 65+ years, log10 transformed values of serum calcium and serum phosphorus were also used as continuous independent variables.

\section{Statistical Analysis}

As previously mentioned, separate multivariate regression models were fitted for those aged 1-11, 12-19, 20-64, and 65+ years old with $\log 10$ transformed values of $25 \mathrm{OHD}$ as dependent variables and covariates/independent variables as defined in the previous section. First order interactions terms between gender, race/ethnicity, obesity, and smoking statuses were also included in the models but were retained in the final models if one or more them were found to be statistically significant at $\alpha=0.05$. All analyses were done using SAS University Edition software (www.sas.com).

\section{Results}

No statistically significant interaction term was detected for the model $\left(\mathrm{R}^{2}=28.2 \%\right.$, actual $\mathrm{N}$ used $\left.=2890\right)$ for those aged $1-11$ years First order interaction term between gender and race/ethnicity $(\mathrm{p}<0.01)$ was found to be statistically significant for the model $\left(\mathrm{R}^{2}=39.3 \%\right.$, actual $\mathrm{N}$ used=2069) for those aged 12-19 years. Statistically significant interactions between gender and race/ethnicity $(\mathrm{p}<0.01)$, gender and obesity $(\mathrm{p}<0.01)$, gender and smoking status $(\mathrm{p}<0.01)$, and race/ethnicity $(\mathrm{p}<0.01)$ were found for the model $\left(\mathrm{R}^{2}=28.7 \%\right.$, actual $\mathrm{N}$ used $\left.=7617\right)$ for those aged 20-64 years. The only interaction that was found to be statistically significant for the model $\left(R^{2}=13.2 \%\right.$, actual $N$ used $\left.=2690\right)$ for those aged $65+$ years was between race/ethnicity and obesity $(p=0.04)$.

The regression coefficients provided in the results below should be carefully interpreted since they are associated with log 10 transformed values of $25 \mathrm{OHD}$ and in case of calcium and phosphorus, regression coefficients are between log 10 transformed values of calcium and phosphorous with $\log 10$ transformed values of $25 \mathrm{OHD}$ levels. For example, in Table 2, for those aged 1-11 years, regression coefficient between age and $\log 10(25 \mathrm{OHD})$ was -0.00832 meaning a unit increase in age is associated with a decrease in the value of $25 \mathrm{OHD}$ equal to $\left(10^{0.00832}-1\right)$ or $0.02 \mathrm{nmol} / \mathrm{L}$. Similarly, a regression coefficient of $0.9036 \mathrm{between}$ $\log 10($ calcium $)$ and $\log 10(25 \mathrm{OHD})$ for those aged $20-64$ years means a unit increase in the value of $\log 10(\mathrm{calcium})$ in $\mathrm{mmol} / \mathrm{L}$ is associated with an increase in the value of $25 \mathrm{OHD}$ equal to $\left(10^{0.9036}-1\right)$ or $7.0 \mathrm{nmol} / \mathrm{L}$.

\begin{tabular}{|c|c|c|c|c|}
\hline & Age: 1-11 Years & Age: 12-19 Years & Age: 20-64 Years & Age: 65+ Years \\
\hline & $\beta(\mathrm{SE}, \mathrm{p})$ & $\beta(\mathrm{SE}, \mathrm{p})$ & $\beta(\mathrm{SE}, \mathrm{p})$ & $\beta(\mathrm{SE}, \mathrm{p})$ \\
\hline Age & $-0.00832(0.001,<0.01)$ & $0.00008(0.003,0.98)$ & $0.00065(0,0.01)$ & $-0.0001(0.001,0.92)$ \\
\hline Poverty Income Ratio & $0.00547(0.002,0.01)$ & $0.01274(0.003,<0.01)$ & $0.00518(0.001,<0.01)$ & $0.00863(0.003,0.01)$ \\
\hline Log10(calcium in mmol/L) & & $1.24702(0.294,<0.01)$ & $0.9036(0.23,<0.01)$ & $1.66821(0.262,<0.01)$ \\
\hline Log10(phosphorus in mmol/L) & & $0.07883(0.084,0.35)$ & $0.08115(0.039,0.04)$ & $0.13577(0.07,0.06)$ \\
\hline
\end{tabular}

Table 2: Regression slopes, $\beta$ (for dependent variable: $\log 10$ transformed values of $25 \mathrm{OHD}$ in nmol/L) with standard errors and p-values for continuous variables by age groups. Data from National Health and Nutrition Examination Survey 2007-2010 


\section{Children aged 1-11 years}

Male children were found to have statistically significantly higher adjusted geometric means (AGM) for 25OHD levels than females children ( 65.4 vs. $63.2 \mathrm{nmol} / \mathrm{L}, \mathrm{p}<0.01$, Table 3$)$. The order in which AGMs for $25 \mathrm{OHD}$ levels by race/ethnicity was observed was NHW $(76.6 \mathrm{nmol} / \mathrm{L})>\operatorname{HISP}(62.7 \mathrm{nmol} / \mathrm{L})>\mathrm{NHB}(55.8 \mathrm{nmol} / \mathrm{L})$ and all pairwise differences were statistically significant $(\mathrm{p}<0.01)$. Compared to NHB, NHW children had about 37\% higher 25OHD levels. AGMs for HISP and OTH were similar ( $\mathrm{p}>0.05$ ). Obese children had statistically significantly lower AGMs for 25OHD than non-obese children (61.9 vs. 66.8 $\mathrm{nmol} / \mathrm{L}, \mathrm{p}<0.01$, Table 3$)$.

\begin{tabular}{|c|c|c|c|c|c|}
\hline & & \multicolumn{2}{|c|}{ Children aged 1-11 Years } & \multicolumn{2}{|r|}{ Adolescents aged 12-19 Years } \\
\hline & & AGM $(95 \%$ CI $)$ & $\begin{array}{l}\text { Statistically Significant } \\
\text { Differences }\end{array}$ & AGM $(95 \%$ CI $)$ & Statistically Significant Differences \\
\hline \multirow{2}{*}{ Gender } & Male (M) & $65.4(63.6-67.2)$ & $\mathrm{M}>\mathrm{F}(\mathrm{p}<0.01)$ & $51.7(49-54.6)$ & $\mathrm{M}>\mathrm{F}(\mathrm{p}=0.01)$ \\
\hline & Female (F) & $63.2(61.4-65.1)$ & & $48.8(45.7-52.1)$ & \\
\hline \multirow{4}{*}{ Race/ethnicity } & $\begin{array}{l}\text { Non-Hispanic } \\
\text { White (NHW) }\end{array}$ & $76.6(73.5-79.9)$ & $\begin{array}{l}\text { NHW }>\text { NHB }(p<0.01), \\
\text { NHW }>\text { HISP }(p<0.01), \\
\text { NHW }>\text { OTH }(p<0.01)\end{array}$ & $68(64.4-71.9)$ & $\begin{array}{c}\text { NHW }>\text { NHB }(p<0.01), \text { NHW }>\text { HISP }(p<0.01) \\
\text { NHW }>\text { OTH }(p<0.01)\end{array}$ \\
\hline & $\begin{array}{l}\text { Non-Hispanic } \\
\text { Black (NHB) }\end{array}$ & $55.8(53.6-58.2)$ & $\begin{array}{l}\text { NHB }<\text { HISP }(\mathrm{p}<0.01) \\
\mathrm{NHB}<\text { OTH }(\mathrm{p}<0.01)\end{array}$ & $38(34.9-41.4)$ & NHB $<$ HISP $(p<0.01)$, NHB $<$ OTH $(p<0.01)$ \\
\hline & $\begin{array}{l}\text { Hispanics } \\
\text { (HISP) }\end{array}$ & $62.7(61.1-64.4)$ & & $50.8(47.7-54)$ & \\
\hline & Others (OTH) & $63.6(59-68.6)$ & & $48.4(43.7-53.7)$ & \\
\hline \multirow{8}{*}{$\begin{array}{l}\text { Gender and } \\
\text { Race/ethnicity }\end{array}$} & M_NHW & & & $66.8(62.9-71)$ & $\begin{array}{c}\text { M_NHW }>\text { M_NHB }(\mathrm{p}<0.01), \text { M_NHW }> \\
\text { M_HISP }(\mathrm{p}<0.01), \text { M_NHW }>\text { M_OTH }(\mathrm{p}<0.01), \\
\text { M_NHB }<\text { M_HISP }(\mathrm{p}<0.01), \text { M_NHB }<\text { M_OTH } \\
\quad(\mathrm{p}<0.01), \text { M_HISP }>\text { M_OTH }(\mathrm{p}<0.01)\end{array}$ \\
\hline & M_NHB & & & $41.1(37.7-44.7)$ & M_NHB > F_NHB $(\mathrm{p}<0.01)$ \\
\hline & M_HISP & & & $54.3(51.4-57.2)$ & M_HISP > F_HISP $(\mathrm{p}<0.01)$ \\
\hline & M_OTH & & & $48(44-52.3)$ & \\
\hline & F_NHW & & & $69.2(65.1-73.6)$ & $\begin{array}{c}\text { F_NHW }>\text { F_NHB }(p<0.01), \text { F_NHW }>\text { F_HISP } \\
(p<0.01), \text { F_NHW }>\text { F_OTH }(p<0.01), \text { F_NHB }< \\
\text { F_HISP }(p<0.01), \text { F_NHB }<\text { F_OTH }(p<0.01)\end{array}$ \\
\hline & F_NHB & & & $35.2(31.8-39)$ & \\
\hline & F_HISP & & & $47.5(43.9-51.4)$ & \\
\hline & F_OTH & & & $48.9(41.6-57.5)$ & \\
\hline \multirow[t]{2}{*}{ Obesity } & $\begin{array}{l}\text { Not Obese } \\
(\mathrm{NOB})\end{array}$ & $66.8(65.2-68.4)$ & NOB $>$ OB $(p<0.01)$ & $53.8(51-56.7)$ & $\mathrm{NOB}>\mathrm{OB}(\mathrm{p}<0.01)$ \\
\hline & Obese (OB) & $61.9(59.9-63.9)$ & & $46.9(43.9-50)$ & \\
\hline \multirow[t]{2}{*}{ Smoking Status } & $\begin{array}{l}\text { Non-smoker } \\
\quad(\text { NSM })\end{array}$ & & & $49.5(47.4-51.7)$ & \\
\hline & Smoker (SM) & & & $50.9(46.6-55.6)$ & \\
\hline
\end{tabular}

Table 3: Adjusted geometric means (AGM) with 95\% confidence intervals in nmol/L for 25-hydroxyvitamin D by gender, race/ethnicity, and obesity for children aged 1-11 years and adolescents aged 12-19 years. Data from National Health and Nutrition Examination Survey 2007-2010

The levels of $25 \mathrm{OHD}$ decreased with increase in age among children $(\beta=-0.00832, \mathrm{p}<0.01$, Table 2$)$. PIR was positively associated with $25 \mathrm{OHD}$ levels $(\beta=0.00547, \mathrm{p}=0.01$, Table 2$)$.

\section{Adolescents aged 12-19 years}

For both NHB (41.1 vs. $35.2 \mathrm{nmol} / \mathrm{L}$ ) and HISP (54.3 vs. $47.0 \mathrm{nmol} / \mathrm{L}$, Table 3 ), male adolescents had statistically significantly higher ( $\mathrm{p}<0.01$, Table 3) 25OHD levels than females. However, there were no statistically significant differences for $25 \mathrm{OHD}$ levels among NHW adolescents (66.8 vs. $69.2 \mathrm{nmol} / \mathrm{L}, \mathrm{p}>0.05)$. Consequently, observed male-female differences for $25 \mathrm{OHD}$ levels among adolescents were primarily determined by NHB and HISP.

Among both male and female adolescents, the order in which AGMs for 25OHD were observed was NHW $>$ HISP $>$ NHB and all pairwise differences were statistically significant ( $\mathrm{p}<0.01$, Table 3). Among males, the AGMs were 66.8, 54.3, and 41.1 nmol/L for NHW, HISP, and NHB respectively and NHW male adolescents had 63\% higher AGMs than NHB adolescents. Among females, the AGMs were 69.2, 47.5, and $35.2 \mathrm{nmol} / \mathrm{L}$ for NHW, HISP, and NHB respectively and NHW female adolescents had $97 \%$ higher AGMs than NHB adolescents. In other words, differences in 25OHD levels among NHW and NHB were substantially wider among females or $34.0 \mathrm{nmol} / \mathrm{L}$ than they were among males or $25.7 \mathrm{nmol} / \mathrm{L}$. 
Obese adolescents had statistically significantly lower AGMs for 25OHD than non-obese adolescents (46.9 vs. $53.8 \mathrm{nmol} / \mathrm{L}$, $\mathrm{p}<0.01$, Table 3). Smoking did not affect the levels of 25OHD levels among adolescents.

Age did not affect the levels of 25OHD levels among adolescents (Table 2) but higher PIR was associated with increased levels of $25 \mathrm{OHD}(\beta=0.01274, \mathrm{p}<0.01$, Table 2$)$. A statistically significant positive association between $25 \mathrm{OHD}$ and serum calcium levels was observed $(\beta=1.24702, \mathrm{p}<0.01$, Table 2$)$.

\section{Adults aged 20-64 years}

While male NHW were found to have statistically significantly lower levels of 25OHD than females NHW (65.5 vs. 67.8 nmol/L, $\mathrm{p}=0.4$, Table 4), the opposite was true for HISP male-female comparison (53.4 vs. $49.1 \mathrm{nmol} / \mathrm{L}$ ). Among males, the order in which 25OHD levels by race/ethnicity was observed was: NHW > HISP > OTH > NHB and all pairwise differences were statistically significant $(\mathrm{p}<0.01)$. Among females, the order in which $25 \mathrm{OHD}$ levels by race/ethnicity was observed was: NHW $>$ OTH $>$ HISP $>$ NHB and all pairwise differences except between HISP and OTH were statistically significant $(\mathrm{p}<0.01)$. The NHW-HISP difference in AGMs for males was $22.1 \mathrm{nmol} / \mathrm{L}$ and for females, it was $19.7 \mathrm{nmol} / \mathrm{L}$.

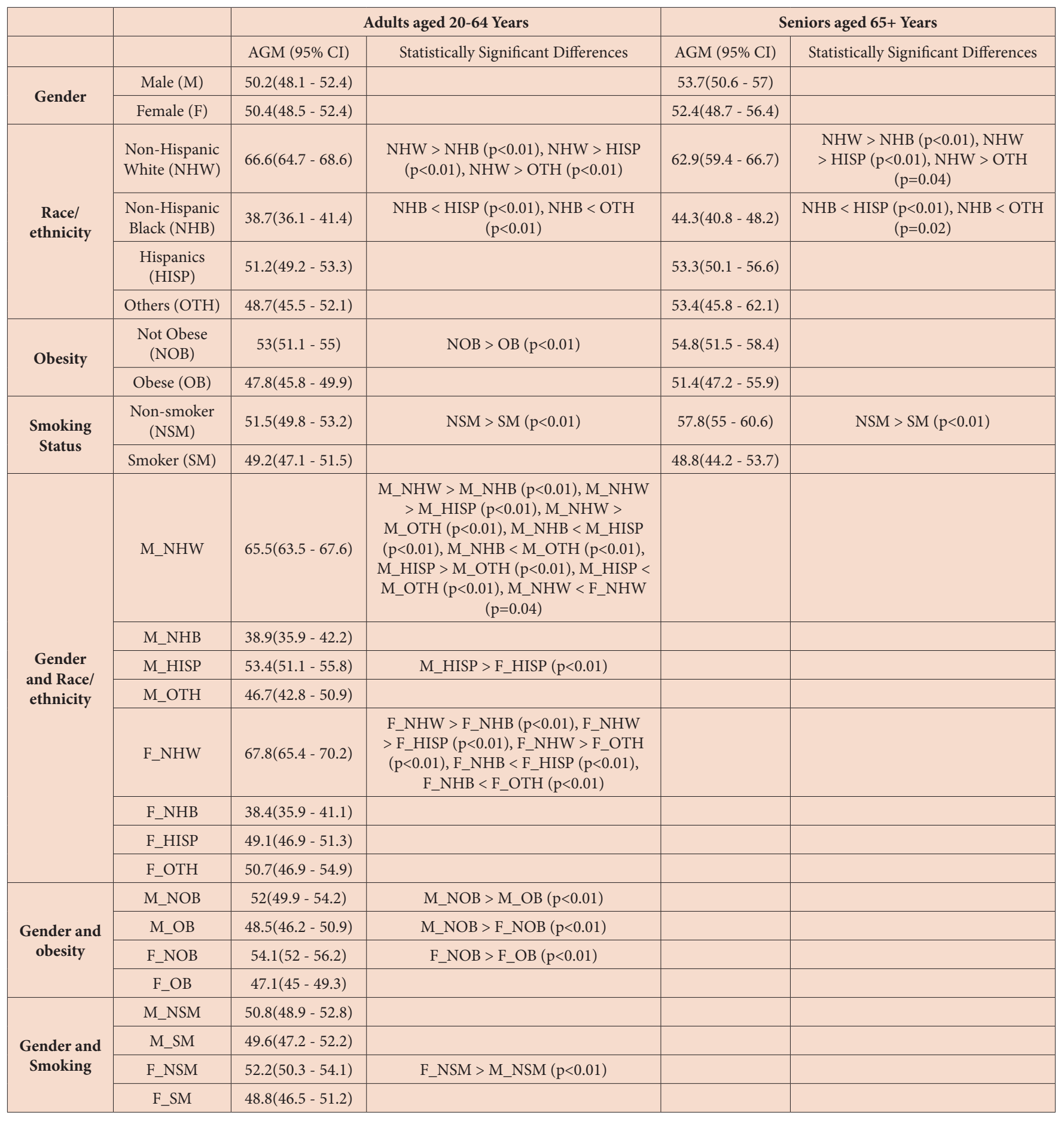




\begin{tabular}{|c|c|c|c|c|c|}
\hline & & \multicolumn{2}{|r|}{ Adults aged 20-64 Years } & \multicolumn{2}{|c|}{ Seniors aged $65+$ Years } \\
\hline & & AGM (95\% CI) & Statistically Significant Differences & $\operatorname{AGM}(95 \% \mathrm{CI})$ & Statistically Significant Differences \\
\hline \multirow{8}{*}{$\begin{array}{l}\text { Race/ } \\
\text { ethnicity } \\
\text { and obesity }\end{array}$} & NHW_NOB & $72.6(70.6-74.6)$ & $\begin{array}{l}\text { NHW_NOB }>\text { NHW_OB }(p<0.01) \text {, } \\
\text { NHW_NOB }>\text { NHB_NOB }(p<0.01) \text {, } \\
\text { NHW_NOB }>\text { HISP_NOB }(p<0.01) \text {, } \\
\text { NHW_NOB }>\text { OTH_NOB }(p<0.01)\end{array}$ & $67.9(64.5-71.5)$ & $\begin{array}{l}\text { NHW_NOB }>\text { NHW_OB }(p<0.01) \text {, } \\
\text { NHW_NOB }>\text { NHB_NOB }(p<0.01) \text {, } \\
\text { NHW_NOB }>\text { HISP_NOB }(p<0.01) \text {, } \\
\text { NHW_NOB }>\text { OTH_NOB }(\mathrm{p}<0.01)\end{array}$ \\
\hline & NHW_OB & $61.2(59-63.4)$ & $\begin{array}{c}\text { NHB_NOB }>\text { NHB_OB }(\mathrm{p}<0.01), N_{H}+ \\
\text { OB }>\text { NHB_OB }(\mathrm{p}<0.01), \text { NHW_OB }> \\
\text { HISP_OB }(\mathrm{p}<0.01), \text { NHW_OB }>\text { OTH_ } \\
\text { OB }(\mathrm{p}<0.01)\end{array}$ & $58.4(54.4-62.6)$ & $\begin{array}{l}\text { NHW_OB }<\text { NHB_OB }(\mathrm{p}<0.01) \\
\text { NHW_OB }>\text { HISP_OB }(<0.01)\end{array}$ \\
\hline & NHB_NOB & $40.5(37.8-43.4)$ & $\begin{array}{l}\text { NHB_NOB }<\text { HISP_NOB }(\mathrm{p}<0.01), \\
\text { NHB_NOB }<\text { OTH_NOB }(\mathrm{p}<0.01)\end{array}$ & $47(42.7-51.7)$ & $\begin{array}{l}\text { NHB_NOB }>\text { NHB_OB }(p=0.03) \text {, } \\
\text { NHB_NOB }<\text { HISP_NOB }(p<0.01)\end{array}$ \\
\hline & NHB_OB & $36.9(34.2-39.8)$ & $\begin{array}{c}\text { NHB_OB }<\text { HISP_OB }(\mathrm{p}<0.01), \mathrm{NHB}_{-} \\
\text {OB }<\text { OTH_OB }(\mathrm{p}<0.01)\end{array}$ & $41.8(37.8-46.3)$ & $\begin{array}{l}\text { NHB_OB }<\text { HISP_OB }(\mathrm{p}<0.01) \\
\text { NHB_OB }<\text { OTH_OB }(\mathrm{p}=0.049)\end{array}$ \\
\hline & HISP_NOB & $54(51.7-56.4)$ & $\begin{array}{c}\text { HISP_NOB }>\text { HISP_OB }(p<0.01), \text { HISP_ } \\
\text { NOB }<\text { OTH_NOB }(p=0.04)\end{array}$ & $54.2(51-57.7)$ & \\
\hline & HISP_OB & $48.5(46.5-50.7)$ & & $52.4(48.2-56.9)$ & \\
\hline & OTH_NOB & $49.8(46.4-53.4)$ & & $52.3(45.4-60.2)$ & \\
\hline & OTH_OB & $47.6(43.3-52.4)$ & & $54.5(42-70.6)$ & \\
\hline
\end{tabular}

Table 4: Adjusted geometric means (AGM) with $95 \%$ confidence intervals in nmol/L for 25-hydroxyvitamin D by gender, race/ethnicty, and obesity for those aged $>=20$ years. Data from National Health and Nutrition Examination Survey 2007-2010

Among both males (52.0 vs. $48.5 \mathrm{nmol} / \mathrm{L}$, Table 4$)$ and females (54.1 vs. $47.1 \mathrm{nmol} / \mathrm{L})$, non-obese had statistically higher AGMs $(\mathrm{p}<0.01)$ for $25 \mathrm{OHD}$ than obese individuals, obese-non-obese difference for females was double of what it was males $(7.0$ vs. $3.5 \mathrm{nmol} / \mathrm{L}$ ). While male non-obese did have statistically significantly higher 25OHD levels than female non-obese individuals $(\mathrm{p}<0.01)$, the same was not observed between male and female obese individuals ( $48.5 \mathrm{vs} .47 .1 \mathrm{nmol} / \mathrm{L})$. While smoking did not affect 25OHD levels in general, female non-smokers did have statistically significantly higher 25OHD levels than male nonsmokers (52.2 vs. $50.8 \mathrm{nmol} / \mathrm{L}, \mathrm{p}<0.01$, Table 4).

Among NHW, NHB, and HISP, non-obese individuals had statistically significantly higher AGMs (p<0.01, Table 4) for 25OHD than obese individuals but non-obese-obese differences were 11.3, 5.5, and $3.6 \mathrm{nmol} / \mathrm{L}$ for NHW, HISP, and NHB respectively. Among non-obese individuals, the order in which AGMs by race/ethnicity were observed was: NHW $>$ HISP $>$ OTH $>$ NHB and all pairwise differences were statistically significant except between HISP and OTH. Among, obese individuals also, NHW > HISP > OTH > NHB and all pairwise differences were statistically significant except between HISP and OTH. However, race-wise differences in AGMs between obese and non-obese varied substantially. For example, while non-obese differences between NHW and NHB was $11.4 \mathrm{nmol} / \mathrm{L}$, it was $3.6 \mathrm{nmol} / \mathrm{L}$ among obese NHW and NHB (Table 4).

The levels of 25OHD were found to increase with increase in age $(\beta=0.0065, \mathrm{p}=0.01$, Table 2$)$ as well as PIR $(\beta=0.00518, \mathrm{p}<0.01$, Table 2). There was also a statistical significant positive association between the levels of $25 \mathrm{OHD}$ and serum calcium ( $\beta=0.9036$, $\mathrm{p}<0.01$, Table 2$)$ as well as serum phosphorus $(\beta=0.08115, \mathrm{p}=0.04$, Table 2$)$.

\section{Seniors aged $65+$ years}

There were no statistically significant different in AGMs for 25OHD among male and female seniors (Table 4). Non-smoker seniors had statistically higher $25 \mathrm{OHD}$ levels than smoker seniors ( $57.8 \mathrm{vs} .47 .8 \mathrm{nmol} / \mathrm{L}, \mathrm{p}<0.01$, Table 4 ) by about $20 \%$.

Both NHW (67.9 vs. $48.4 \mathrm{nmol} / \mathrm{L}, \mathrm{p}<0.01$, Table 4) and NHB non-obese (47.0 vs. $41.8 \mathrm{nmol} / \mathrm{L}, \mathrm{p}<0.01$, Table 4) had statistically significantly higher levels of 25OHD levels than NHW and NHB obese respectively; however, the same was not true for HISP and OTH. Among non-obese seniors, the order of $25 \mathrm{OHD}$ levels by race/ethnicity was: NHW $(67.9 \mathrm{nmol} / \mathrm{L})>\mathrm{HISP}(54.2 \mathrm{nmol} / \mathrm{L})$ $>$ NHB $(47.0 \mathrm{nmol} / \mathrm{L})$ and the differences were statistically significant $(\mathrm{p}<0.01$, Table 4$)$. Among obese seniors also, the order of $25 \mathrm{OHD}$ levels by race/ethnicity was: NHW $(58.4 \mathrm{nmol} / \mathrm{L})>\mathrm{HISP}(52.4 \mathrm{nmol} / \mathrm{L})>\mathrm{NHB}(41.8 \mathrm{nmol} / \mathrm{L})$ and the differences were statistically significant $(\mathrm{p}<0.01$, Table 4$)$.

The levels of $25 \mathrm{OHD}$ were found to increase with increase PIR $(\beta=0.00863, p=0.01$, Table 2$)$. There was a statistically significant positive association between the levels of $25 \mathrm{OHD}$ and serum calcium $(\beta=1.66821, \mathrm{p}<0.01$, Table 2$)$ but no statistically significant association was found with serum phosphorus $(\beta=0.13577, \mathrm{p}=0.06$, Table 2$)$.

\section{Discussion}

\section{Impact of gender and race/ethnicity}

In a study of 634 healthy adults aged 18-50 years, Mitchell, et al. reported 25OHD levels to be higher among NHW than NHB (31 ng/mL vs. $17 \mathrm{ng} / \mathrm{mL}$ ) and females to have higher levels than males (30 ng/mL vs. $24 \mathrm{ng} / \mathrm{mL}$ ) [25]. Looker, et al. also reported 25OHD levels to be in the order NHW > Mexican Americans > NHB but males to have higher levels than females [26]. In patients 
undergoing coronary angiography, females were reported to have lower vitamin D levels than males Verdoia, et al. [27]. In this study vitamin D levels based on LC-MS/MS measurements were not found to be statistically significantly difference between males and females aged $>=20$ years but among children as well as adolescents, males were found to be statistically significantly higher levels than females but the differences were small, namely, $2.2 \mathrm{nmol} / \mathrm{L}$ for children and $2.9 \mathrm{nmol} / \mathrm{L}$ among adolescents. As was found by Looker, et al. and Mitchell, et al. (2012), the order of 25OHD levels by race/ethnicity in this study for those aged $>=$ 20 years, was observed to be NHW > HISP > NHB and pairwise differences were statistically significantly different [25,26]. The order of $25 \mathrm{OHD}$ levels by race/ethnicity for children and adolescents was also observed to be the same. NHB have been reported to have lower $25 \mathrm{OHD}$ levels because of the fact that pigmentation reduces vitamin $\mathrm{D}$ production in skin as well as lower vitamin $\mathrm{D}$ intake by NHB as compared with other racial/ethnic groups Harris [28]. Metabolic differences based in race/ethnicity may provide additional explanation.

\section{Impact of age}

While no formal statistical comparisons were made, children were found to have substantially higher 25OHD levels than adolescents irrespective of gender and race/ethnicity. Adults aged 20-64 years had lower levels than seniors aged $>=65$ years for males 50.2 vs. $53.7 \mathrm{nmol} / \mathrm{L}$ ), females ( 50.4 vs. $52.4 \mathrm{nmol} / \mathrm{L}$ ), and NHB (38.7 vs. $44.3 \mathrm{nml} / \mathrm{L}$ ) but the reverse was true for NHW ( 66.6 vs. $62.9 \mathrm{nmol} / \mathrm{L})$. In addition, among children, $25 \mathrm{OHD}$ levels decreased with age $(\mathrm{p}<0.01)$ and among adults, they increased with age $(\mathrm{p}=0.01)$. However, Fujisawa, et al. did not find any age related changes in 25OHD levels among children, younger and older adults [29]. Tsai, et al. also did not observe any age related changes in 25OHD levels in Chinese females aged 18-80 years except lowering of these levels at the two extremes of ages [30]. Age related changes in 25OHD levels observed in this study may be associated with changes in vitamin $\mathrm{D}$ intake and/or metabolic changes associated with ageing.

\section{Association with calcium and phosphorus}

Positive association between vitamin D levels and serum calcium and phosphorus observed in this study is in conformity with the essential role that vitamin D plays in calcium and phosphorus homeostasis as suggested by Tsiaras, et al. [31]. A deficiency in Vitamin D may be associated with deficiency in both calcium and phosphorous or vice versa.

\section{Impact of obesity}

Wallace, et al. (2013) reported low income and overweight to have lower levels of vitamin D which is similar to what was found in this study [32].

\section{Impact of smoking}

Smokers were found to have lower levels of 25OHD for both 20-64 and $\geq 65$ years old. This means certain constituents in tobacco smoke may adversely affect the levels of Vitamin D and as such smokers may be faced with adverse consequences associated with Vitamin D deficiency to a larger extent than non-smokers.

\section{Impact of PIR}

Low PIR was found to be associated with lower levels of 25OHD. These results are in conformity with those reported by Moore, et al. because lower Vitamin D intake is associated with low PIR [33,34].

\section{Strengths and limitations of the study}

The primary strength of the study lies in the fact these analyses were based on a large, nationally representative sample of U.S. children, adolescents, adults, and senior citizens and as such, generalizations can be made without undue reservations. On the other hand, the study was based on cross-sectional data and as such, conclusions cannot be necessarily arrived at about how Vitamin D levels may vary from childhood to adulthood over the life-time of U.S. citizens.

\section{Summary and conclusions}

In summary, (i) male children and adolescents were found to have higher levels of 25OHD than female children and adolescents respectively, (ii) the order of 25OHD levels by race/ethnicity was NHW > HISP > NHB, (iii) obesity was associated with lower levels of 25OHD, (iv) smoking was associated with lower levels of 25OHD, (v) PIR was positively associated with the levels of 25OHD, and (vi) for children, age was negatively associated with 25OHD levels and among adults aged 20-64 years, age was positively associated with $25 \mathrm{OHD}$ levels.

\section{References}

1. Holick MF (2004) Sunlight and vitamin D for bone health and prevention of autoimmune diseases, cancers, and cardiovascular diseases. Am J Clin Nutr 80: 1678S-88S.

2. Gutiérrez OM, Farwell WR, Kermah D, Taylor EN (2011) Racial differences in the relationship between vitamin D, bone mineral density, and parathyroid hormone in the National Health and Nutrition Examination Survey. Osteoporos Int 22: 1745-53.

3. Ganji V, Zhang X, Shaikh N, Tangpricha V (2011) Serum 25-hydroxyvitamin D concentrations are associated with prevalence of metabolic syndrome and various cardiometabolic risk factors in US children and adolescents based on assay-adjusted serum 25-hydorxyvitamin D data from NHANES 2001-2006. Am J Clin Nutr 94: 225-33. 
4. Maki KC, Fulgoni VL $3^{\text {rd }}$, Keast DR, Rains TM, Park KM, et al. (2012) Vitamin D intake and status are associated with lower prevalence of metabolic syndrome in U.S. adults: National Health and Nutrition Examination Surveys 2003-2006. Metab Syndr Relat Disord 10: 363-72.

5. Frei R, Haile SR, Mutsch M, Rohrmann S (2015) Relationship of Serum Vitamin D Concentrations and Allostatic Load as a Measure of Cumulative Biological Risk among the US Population: A Cross-Sectional Study. PLoS One 10: e0139217.

6. Quraishi SA, Bittner EA, Christopher KB, Camargo CA (2013) Vitamin D status and community-acquired pneumonia: results from the third National Health and Nutrition Examination Survey. PLoS One 8: e81120.

7. Monlezun DJ, Bittner EA, Christopher KB, Camargo CA, Quraishi SA (2015) Vitamin D status and acute respiratory infection: cross sectional results from the United States National Health and Nutrition Examination Survey, 2001-2006. Nutrients 7: 1933-44.

8. Atkinson MA, Eisenbarth GS, Michels AW (2014) Type 1 diabetes. Lancet 4: 69-82.

9. Williams DM, Fraser A, Lawlor DA (2011) Associations of vitamin D, parathyroid hormone and calcium with cardiovascular risk factors in US adolescents Heart 97: 315-20.

10. He JL, Scragg RK (2011) Vitamin D, parathyroid hormone, and blood pressure in the National Health and Nutrition Examination Surveys . Am J Hypertens 24: $911-7$

11. Liangpunsakul S, Chalasani N (2011) Serum vitamin D concentrations and unexplained elevation in ALT among US adults. Dig Dis Sci 56: $2124-9$.

12. Wilhelm-Leen ER, Hall YN, Deboer IH, Chertow GM (2010) Vitamin D deficiency and frailty in older Americans. J Intern Med 268: 171-80.

13. Soderstrom LH, Johnson SP, Diaz VA, Mainous AG (2012) Association between vitamin D and diabetic neuropathy in a nationally representative sample: results from 2001-2004 NHANES. Diabet Med 29: 50-5.

14. Zhang M, Cheng K, Rope R, Martin E, Jetmalani A (2013) Do children with mental disorders have higher prevalence of hypovitaminosis D? F1000Res 2: 159.

15. Milman S, Schulder-Katz M, Deluty J, Zimmerman ME, Crandall JP, et al. (2014) Individuals with exceptional longevity manifest a delayed association between vitamin D insufficiency and cognitive impairment. J Am Geriatr Soc 62: 153-8.

16. Schmutz EA, Zimmermann MB, Rohrmann S (2015) The inverse association between serum 25-hydroxyvitamin D and mortality may be modified by vitamin A status and use of vitamin A supplements. Eur J Nutr 55: 393-402.

17. Zhao G, Ford ES, Tsai J, Li C, Croft JB (2012) Factors Associated with Vitamin D Deficiency and Inadequacy among Women of Childbearing Age in the United States. Obstet Gynecol doi.org/10.5402/2012/691486.

18. Deng X, Song Y, Manson JE, Signorello LB, Zhang SM, et al. (2013) Magnesium, vitamin D status and mortality: results from US National Health and Nutrition Examination Survey (NHANES) 2001 to 2006 and NHANES III. BMC Med 11: 187.

19. Cheng TY, Neuhouser ML (2012) Serum 25-hydroxyvitamin D, vitamin A, and lung cancer mortality in the US population: a potential nutrient-nutrient interaction. Cancer Causes Control 23: 1557-65.

20. Michos ED, Reis JP, Post WS, Lutsey PL, Gottesman RF, et al. (2012) 25-Hydroxyvitamin D deficiency is associated with fatal stroke among whites but not blacks: The NHANES-III linked mortality files. Nutrition 28: 367-71.

21. Bakhru A, Mallinger JB, Buckanovich RJ, Griggs JJ (2010) Casting light on 25-hydroxyvitamin D deficiency in ovarian cancer: a study from the NHANES. Gynecol Oncol 119: 314-8.

22. Freedman DM, Looker AC, Abnet CC, Linet MS, Graubard BI (2010) Serum 25-hydroxyvitamin D and cancer mortality in the NHANES III study (1988-2006). Cancer Res 70: 8587-97.

23. CDC (2015) Centers for Disease Control. Analytic notes for 25-hydroxyvitamin D analysis using NHANES III (1988-1994) NHANES 2001-2006, and NHANES 2007-2010 October 2015).

24. Jain RB (2016) Recent vitamin D data from NHANES: variability, trends, deficiency and sufficiency rates, and assay compatibility issues. J Adv Nutr Human Metabol 2: e1208.

25. Mitchell DM, Henao MP, Finkelstein JS, Burnette-Bowie SA (2012) Prevalence and predictors of vitamin D deficiency in health adults. Endocr Pract 18: 914-23.

26. Looker AC, Dawson-Hughes B, Calvo MS, Gunter EW, Sayhoun NR (2002) Serum 25-hydroxyvitamin D status of adolescents and adults in two seasonal subpopulations from NHANES III. Bone 30: 771-7.

27. Verdoia M, Schaffer A, Barbieri L, Di Giovine G, Marino P, et al. (2015) Impact of gender difference on vitamin D status and its relationship with the extent of coronary artery disease. Nutr Metab Cardiovasc Dis 25: 464-70.

28. Harris SS (2006) Vitamin D and African Americans. J Nutr 136: 1126-9.

29. Fujisawa Y, Kida K, Matsuda H (1984) Role of change in vitamin D metabolism with age in calcium and phosphorus metabolism in normal human subjects. J Clin Endocrinol Metab 59: 719-26.

30. Tsai KS, Chen JS, Hwang KM, Chieng PU, Su CT (1991) Age-related changes in vitamin D metabolites, osteocalcin, alkaline phosphatase and parathyrin in normal Chinese women in Taipei. J Formos Med Assoc 90: 1033-7.

31. Tsiaras WG, Weinstock MA (2011) Factors affecting vitamin D status. Acta Derm Venereol 91: 115-24.

32. Wallace TC, Reider C, Fulgoni VL $3^{\text {rd }}$ (2013) Calcium and vitamin D disparities are related to gender, age, race, household income level, and weight classification but not vegetarian status in the United States: Analysis of the NHANES 2001-2008 data set. J Am Coll Nutr 32: 321-30.

33. Moore CE, Radcliffe JD, Liu Y (2014) Vitamin D intakes of children differ by race/ethnicity, sex, age, and income in the United Sates, 2007-2010. Nutr Res 34: 499-506.

34. Moore CE, Radcliffe JD, Liu Y (2014) Vitamin D intakes of adults differ by income, gender and race/ethnicity in the U.S.A., 2007-2010. Public Health Nutr 17: 756-63. 


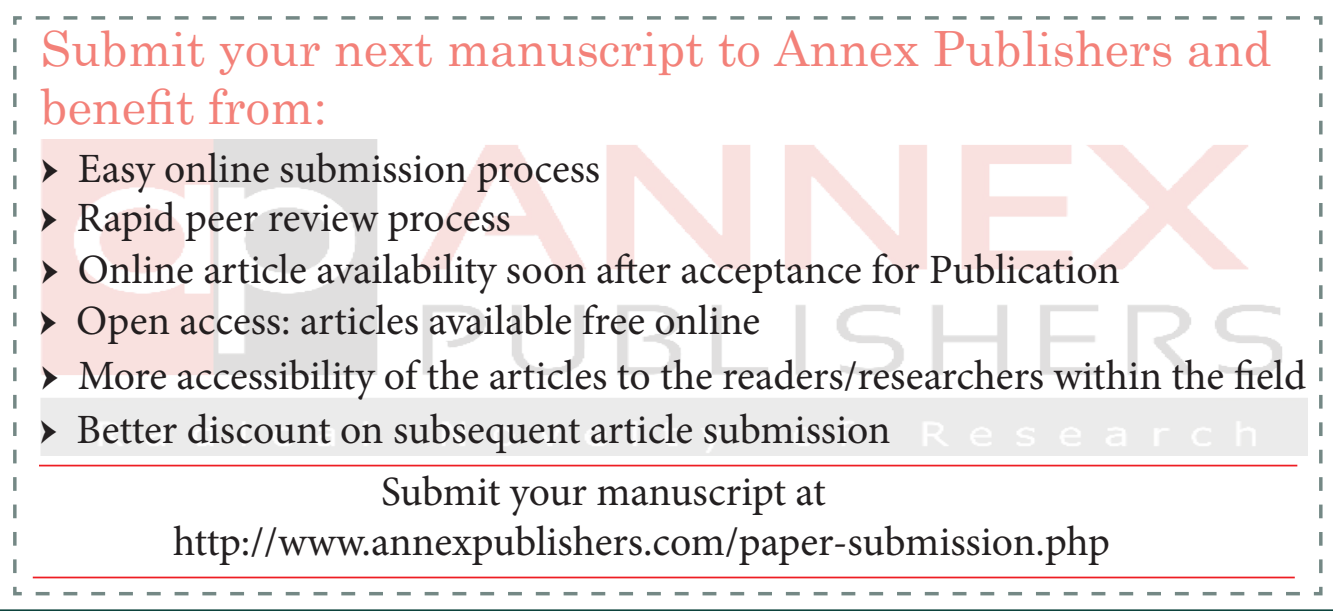

